\title{
Attitude towards generic drugs: A comparative study among clinicians and pharmacy professionals
}

\author{
Sai Kiran Pasupula1, Yalamanchili Sanjay ${ }^{2, *}$, Chilukuri Raviteja ${ }^{3}$ \\ ${ }^{\mathbf{1}}$ Assistant Professor, ${ }^{2}$ Associate Professor, ${ }^{3}$ Resident, Det. of Psychiatry, KMC\&H, Guntur, Andhra Pradesh, India
}

*Corresponding Author: Yalamanchili Sanjay

Email: psai1986@rediff mail.com

\begin{abstract}
Introduction: Generic medicines play a prominent role in pharmaco-economics by providing medicines at a much less price. Generic formulations usage is increasing as they provide the same therapeutic effect as branded medicines at a much more economical price. Attitude towards the usage of generic medicines plays a key role in the usage of these medicines by the pharmacist and clinicians. As limited data is available in this area the current study focuses on attitude towards the generic medicine usage of physicians and pharmacists. Materials and Methods: The current study was conducted at KMC\&H and Hindu college of pharmacy. After prior ethical clearance, attitude towards the generic formulations was measured using ATGM scale and questionnaire among the physicians, pharmacy professionals and general population. Statistical analysis was done using EPIINFO software.

Results and Conclusion: Both Groups believe that Generic medicines do not produce more side-effects than brand name medicines. Pharmacy group has more positive attitude towards most of the items in this questionnaire. In conclusion, more Positive attitude is observed in the pharmacy group than the medical group. This indicates there is a need to increase the awareness among the medical professionals regarding generic formulations.
\end{abstract}

Keywords: Generics, Attitude, Pharmacy.

\section{Introduction}

The major challenge faced by many health care providers and policy makers in the world is the ever escalating health care costs. Within this context, the cost of pharmaceuticals constitutes the second largest cost in health care provision after the staffing costs. The situation is worsening in low-and middle-income countries (LMICs) where the house-hold out-of-pocket payments are a higher proportion of the total expenditure than in high income countries. In this challenging scenario of health care provision especially after the economic crisis in Greece, ${ }^{1}$ one of the mechanisms suggested to minimize the costs of medicines is the encouragement of greater use of generic medicines.

WHO defines generic medicine as "a pharmaceutical product usually intended to be interchangeable with an innovator product that is manufactured without a license from the innovator company and marketed after the expiry date of the patent or other exclusive rights. ${ }^{2}$ Cost of some medicines is a matter of concern especially to poor patients. In response to this government made it compulsory for doctors to write generic names on prescriptions.

This has to some extent reduced expenditure on drugs for patient with chronic disorders. However this substitution of brand name drug with generic drug is not universally accepted due to various patient and physician factors.

Attitude towards generic drugs are varying among physicians and pharmacists, who are the most important people influencing generic drug usage trends in the population. ${ }^{3}$ Previous research suggests that it is not based on any solid evidence, rather on anecdotal reports. Although doctors have good knowledge and positive attitude towards generic medicines, they are concerned about safety, quality and efficacy of these drugs. Thus there is need of clear definitions and more research in this field. ${ }^{4}$

In an Indian study by Chittaranjan Andrade,${ }^{5}$ author attempted to give clear definitions regarding generic drug which are as follows:

1. Branded drugs: A drug that is marketed under a trade name by the company that first brought to the market, regardless of whether or not the patent on the drug has expired. Branded drugs are promoted by medical representatives to medical practitioners.

2. Pharmacological generic: A drug that is marketed under its pharmacological name. In popular parlance, such drugs are sometimes called "generic generics."

The above gap in knowledge needs to be addressed and the current study is an attempt to narrow the gap.

\section{Generic Drugs and Psychiatry}

As a Member of Jana aushadh committee along with counsellor and Clinical Pharmacist, psychiatrist has to create awareness to the fellow doctors and to the common people along with Other Non-governmental organizations. Case reports on generic psychotropic drugs show that generic antidepressants were as good as branded drugs while generic antipsychotics were inferior to their branded counterparts. ${ }^{6}$ As many of the psychiatric disorders are chronic disorders, there will be definite impact of generic drugs.

\section{Aims and Objectives}

1. To study the attitude towards generic formulation among Pharmacists.

2. To study the attitude towards generic formulation among Clinicians.

3. To compare the attitude towards generic formulation among the two groups. 


\section{Materials and Methods}

We took up the study after clearance from the Institutional Ethical Committee. It was a cross sectional study, in which we used a self-administered structured paper questionnaire (Attitude towards Generic Medicines questionnaire). This questionnaire has been validated and used extensively. ${ }^{7-9}$ We also used a semi structured questionnaire for collection of socio-demographic data. All faculty members, holding post graduate degrees in their respective fields who gave their consent for participation in the survey were included, convenience sampling was done. Data collection was carried out in a tertiary care hospital and a local college of pharmacy, over 2 weeks. Out of the 210 people approached for the study, 182 people gave their consent, so, they were included in the study. The two questionnaires were administered to the two groups viz. Medical $(\mathrm{n}=96)$ \& Pharmacy $(\mathrm{n}=86)$.
Inclusion Criteria: All clinicians in the hospital and All faculty members in the Pharmacy College willing to give written informed consent for the study.

Exclusion Criteria: Doctors of Pre and Para-clinical departments and individuals who did not give consent.

\section{Statistical Analysis}

Statistical analysis was done using EPIINFO software.

\section{Results and Discussion}

The socio-demographic characteristics of the study population are described in Table 1.

The current study advances the previous studies in comparing the attitudes towards generic usage among medical individuals and pharmacists.

Table 1

\begin{tabular}{|c|c|c|}
\hline \multicolumn{3}{|l|}{ Gender } \\
\hline & Medical group & Pharma group \\
\hline Male & 44 & 41 \\
\hline Female & 52 & 45 \\
\hline \multicolumn{3}{|l|}{ Age Groups } \\
\hline $25-29$ & 23 & 20 \\
\hline $30-34$ & 25 & 22 \\
\hline $35-39$ & 16 & 12 \\
\hline $40-44$ & 10 & 11 \\
\hline $45-49$ & 8 & 10 \\
\hline $50-54$ & 6 & 8 \\
\hline $55-59$ & 5 & 2 \\
\hline$>60$ & 3 & 1 \\
\hline \multicolumn{3}{|l|}{ Marital Status } \\
\hline Married & 84 & 72 \\
\hline Unmarried & 12 & 14 \\
\hline \multicolumn{3}{|l|}{ Experience } \\
\hline \multicolumn{3}{|c|}{ Clinical Departments Speciality-wise distribution } \\
\hline Speciality & Number & Percentage \\
\hline Anaesthesia & 8 & 8.33 \\
\hline Dermatology & 8 & 8.33 \\
\hline Paediatrics & 8 & 8.33 \\
\hline Ophthalmology & 6 & 6.25 \\
\hline Orthopaedics & 10 & 10.42 \\
\hline Psychiatry & 4 & 4.17 \\
\hline Gynaecology & 9 & 9.38 \\
\hline Surgery & 10 & 10.42 \\
\hline Critical Care & 11 & 11.46 \\
\hline ENT & 4 & 4.17 \\
\hline General Medicine & 10 & 10.42 \\
\hline Pulmonology & 8 & 8.33 \\
\hline \multicolumn{3}{|c|}{ Pharmacology Departments Speciality-wise distribution } \\
\hline Pharmaceutics & 11 & 11.46 \\
\hline Pharmacy Practice & 9 & 9.38 \\
\hline Pharmacology & 12 & 12.50 \\
\hline Pharmaceutical Analysis & 10 & 10.42 \\
\hline Pharmaceutical Chemistry Organic & 11 & 11.46 \\
\hline Pharmaceutical Chemistry Inorganic & 13 & 13.54 \\
\hline Pharmacognosy & 7 & 7.29 \\
\hline
\end{tabular}




\begin{tabular}{|l|c|c|}
\hline Religion & Medical & Pharma \\
\hline Hindu & 42 & 36 \\
\hline Muslim & 34 & 28 \\
\hline Christian & 14 & 18 \\
\hline Others & 6 & 29 \\
\hline Experience & \multicolumn{2}{|l|}{} \\
\hline 1 to 5 Years & 31 & 21 \\
\hline 6 to 10 Years & 23 & 18 \\
\hline 11 to 15 Years & 16 & 13 \\
\hline 16 to 20 Years & 16 & 5 \\
\hline More than 20 years & 10 & 32 \\
\hline Salary per month (in INR) & 0 & 28 \\
\hline$<24,999$ & 34 & 18 \\
\hline $25000-49999$ & 28 & 8 \\
\hline $50000-74999$ & 18 & 0 \\
\hline $75000-99999$ & 16 & \\
\hline$>100000$ & & \\
\hline
\end{tabular}

\section{Responses to the questionnaire}

\section{Graph 1: Clinicians - favorable responses}

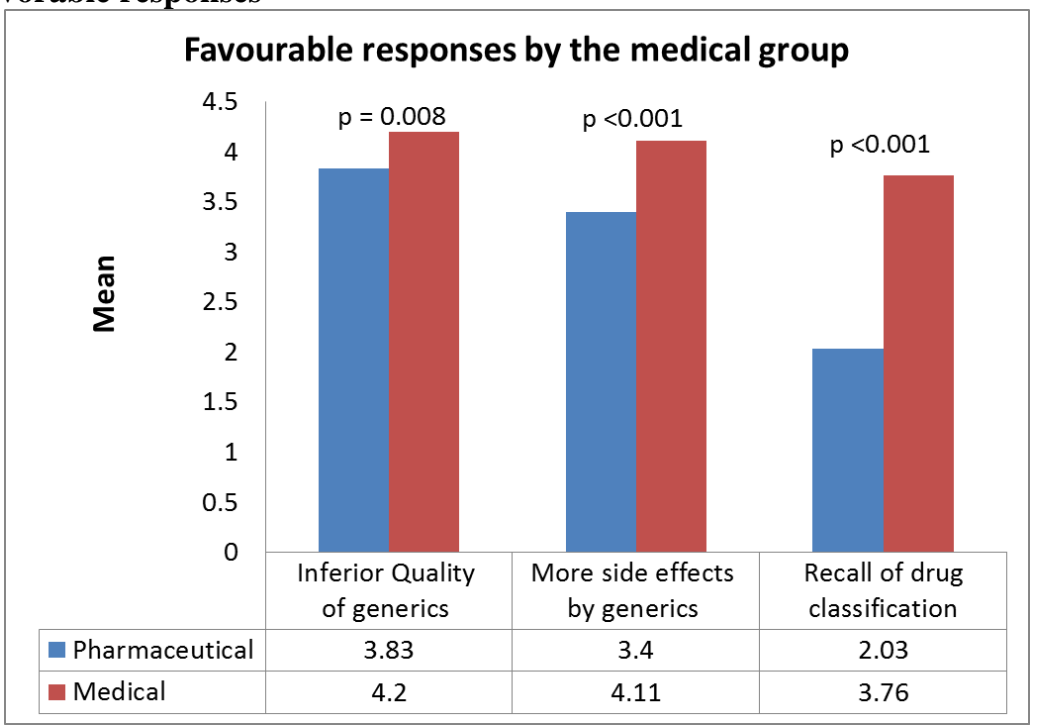

Graph 1 shows the three items on which the clinicians agreed more strongly than the pharmaceutical group, with their means and $p$ values.

Among the medical group, most of the individuals are strongly agreeing that generic medicines have equal therapeutic effects with branded medicines which is similar to the finding of the earlier study. ${ }^{10}$ Among the two groups, pharmacists group strongly disagrees with the statement that Generic medicines produce more side-effects than brand name medicines which is similar to the findings of the previous studies. ${ }^{11,12}$ Current study also found the similar results. 


\section{Graph 2: Pharma favorable responses}

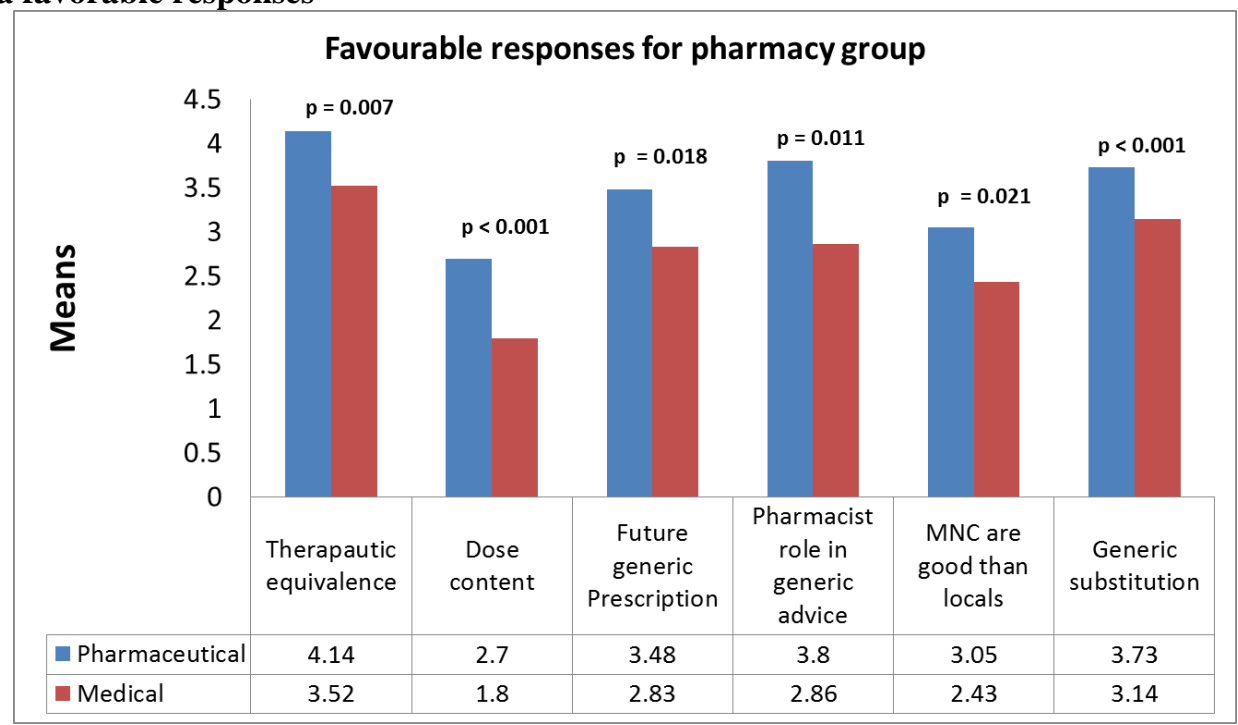

Graph 2 shows the six items on which the pharmaceutical agreed more strongly than the clinicians group, with their means and $p$ values.
Pharmacy group had positive attitude for most of the items which is in contradiction to the study done by Colgan et al. ${ }^{13}$ This can be explained by many factors like increased awareness about generic drugs, availability of the generic formulations and health insurance factors.

\section{Graph 3: Equal responses by two groups}

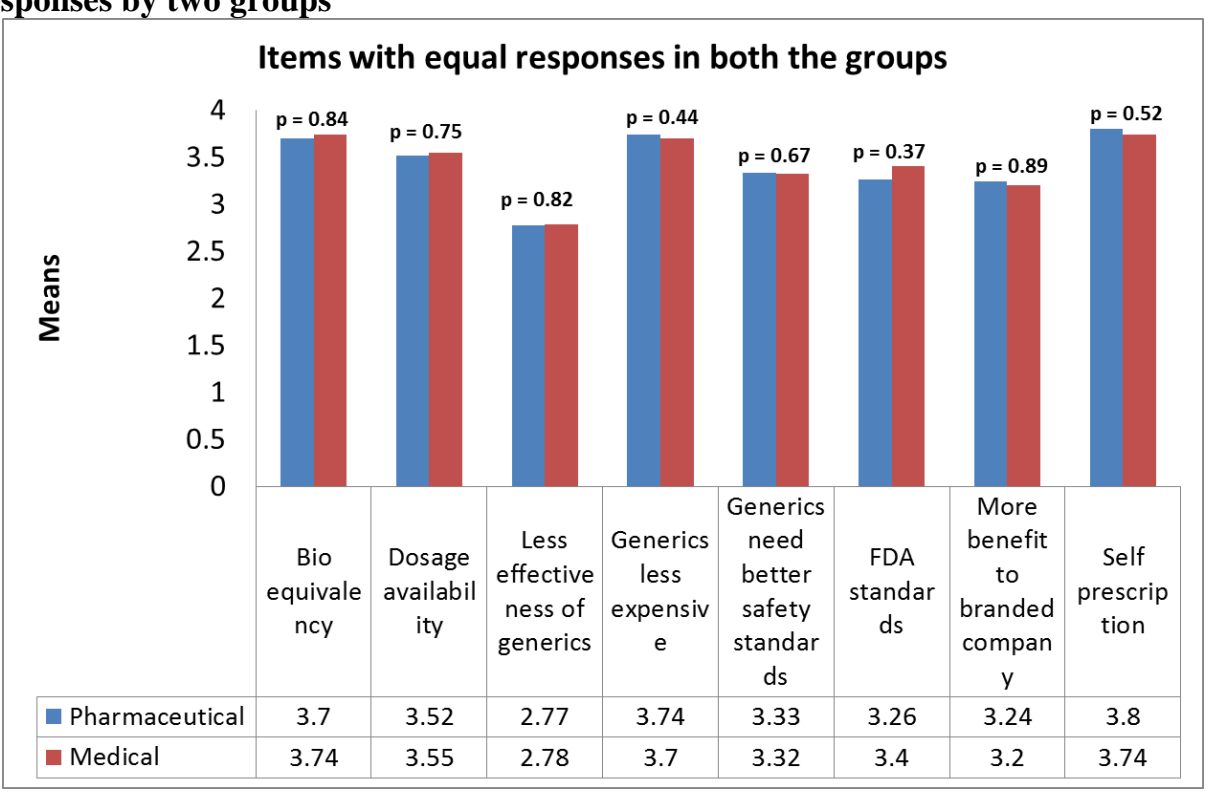

Graph 3 shows the eight items on which the pharmaceutical and clinician groups had equal responses, reflecting no difference between the two groups, with their means and $p$ values (not statistically significant)

In the current study, females have more positive attitude than males in most of the items of the questionnaire, which is against to the findings of the earlier study of Aggeliki V. Tsaprantzi. ${ }^{14}$

Among the departments in the hospital, the department of ENT had the best overall view regarding generic medicines, while dept of Ophthalmology had the least favourable opinion.
Earlier study on brand drug prescriptions suggested ophthalmology is the major branch for prescribing of branded drugs followed by internal medicine, family medicine, cardiology and psychiatry. In that study, they found that the drug company payments mirror doctors' brand-name prescribing. ${ }^{15}$

Among the pharmacy departments, department of Pharmacognosy had the least favorable opinion, which differed from the other departments $(p=0.001)$. This could be attributed to personal idiosyncrasies of the respondents.

Psychiatrists in our sample had a more favourable attitude towards generic drugs overall, but since the sample 
was small $(n=4)$, this cannot be extrapolated to the psychiatrist population of our country.

Among the total sample, on applying the Pearson Correlation, there was statistically significant negative correlation $(\mathrm{r}=-0.762$ to $-0.907, \mathrm{n}=182)$ between most items favouring generic drugs and years of experience of the individuals. $(\mathrm{p}=0.001)$.

\section{Conclusion}

Recent government rules have made compulsory quality testing for generic drugs which is bound to improve the quality of these drugs. Vigorous advertising for popularising of generic drugs highlighting their efficacy and safety is needed for increasing usage and prescription of generic drugs. Positive attitude is observed more among the pharmacy professionals than medical group which signifies the need to increase the awareness of generic formulation to the medical professionals. The attitude towards generic drugs becomes more positive with experience which indicates the need to create awareness towards generic drugs among young professionals. Policy makers need to initiate more awareness programmes at hospital as well as society level to promote the public health awareness and hence reduce the pharmacological economic burden on people.

\section{Limitations}

As the sample is recruited from single institutes, external validity of the study is poor.

\section{Acknowledgment: Nil.}

\section{Conflicts of Interest: Nil.}

\section{References}

1. Notara V., Koupidis S.A., Vaga E. and Grammatikopoulos I.A. 2010: Economic crisis and challenges for the Greek healthcare system: the emergent role of nursing management. J Nurs Manag. 2010;18:501-504.

2. Alfonso-Cristancho R., Andia T., Barbosa T., Watanabe J. H. (2015). Definition and classification of generic drugs across the world. Appl. Health Econ Health Policy. 2015;13:5-11. 10.1007/s40258-014-0146-1.

3. Hassali M.A., Kong D., Stewart K. A comparison between senior medical students' and pharmacy pre-registrants' knowledge and perceptions of generic medicines. Med Educ. 2007;41:703-710.

4. Gupta SK, Nayak RP, Vidyarthi SK. A study on the knowledge, attitude, and practice of generic medicines among the doctors in a tertiary care teaching hospital in South India. Natl J Physiol Pharm Pharmacol. 2015;5:39-44.

5. Andrade C, Rao T S. Prescription writing: Generic or brand?. Indian J Psychiatry. 2017;59:133-137.

6. Bhat V, Margolese HC. Generic formulations of psychotropic medications and treatment response. $J$ Psychiatry Neurosci. JPN. 2017;42(2):E3-E4.

7. Shraim NY, Al Taha TA, Qawasmeh RF. Knowledge, attitudes and practices of community pharmacists on generic medicines in Palestine: a cross-sectional study. BMC Health Serv Res. 2017; $17: 847$.

8. Chua GN, Hassali MA, Shafie AA, Awaisu A. A survey exploring knowledge and perceptions of general practitioners towards the use of generic medicines in the northern state of Malaysia. Health policy. 2010;95(2-3):229-235.

9. Ali FR, Khaliq SA, Zehra S, Khan HA, Azhar I. Knowledge and perception of undergraduate students about generic drugs and their attitude towards generic substitution in Karachi, Pakistan. Int J Pharm. 2013;3(4):689-691.

10. Yard B. Assessment of Knowledge, Attitude and Practice of Pharmacy Professionals toward Generic Medicines, Northern Ethiopia, Mekelle: A Cross Sectional Study. J Basic Clin Pharma. 2017;8:193-119.

11. Ahire K, Shukla M, Gattani M, Singh V, Singh M. A surveybased study in current scenario of generic and branded medicines. Int J Pharm Pharm Sci. 2013;5:705-11.

12. Heikkilä R, Mäntyselkä $P$, Ahonen R. Do people regard cheaper medicines effective? Population survey on public opinion of generic substitution in Finland. Pharmacoepidemiol Drug Saf. 2011;20:185-191.

13. Colgan S, Faasse K, Martin LR, Stephens MH, Grey A, Petrie KJ. Perceptions of generic medication in the general population, doctors and pharmacists: a systematic review. BMJ Open. 2015;5(12):e008915. Published 2015 Dec 15. doi:10.1136/bmjopen-2015-008915

14. Tsaprantzi AV, Kostagiolas P, Platis C, Aggelidis VP, Niakas D. The Impact of Information on Doctors' Attitudes toward Generic Drugs. Inquiry. 2016;53:0046958016637791. Published 2016 Mar 31. doi:10.1177/0046958016637791

15. Ornstein, C. (2016, March 17). Drug-Company Payments Mirror Doctors' Brand-Name Prescribing. Retrieved from https://www.npr.org/sections/healthshots/2016/03/17/470679452/drug-company-payments-mirrordoctors-brand-name-prescribing. 